\title{
Exploring the success factors of eCRM strategies in practice
}

Received: 11th August, 2003

\section{Qimei Chen}

is assistant professor of marketing in the College of Business Administration at the University of Hawaii at Manoa. Her research interests include advertising effectiveness, e-commerce, IT usage and cross-culture consumer behaviour. She is a member of Association of Consumer Research and American Marketing the Association. She also serves on the advertising research committee of the American Academy of Advertising.

\section{Hong-Mei Chen}

is an associate professor of information technology management in the College of Business Administration at the University of Hawaii at Manoa. She is the founder and Director of the Advanced Information Management Solution (AIMS) Laboratory. Her current research interests include business and information technology alignment, distributed multimedia databases, high performance telemedicine, electronic Customer Relationship Management (eCRM) systems, and humanisation in eCommerce systems. She is a member of IEEE Computer, the Association of Information Systems (AIS), and the Association of Computing Machinery (ACM).

\begin{abstract}
Electronic Customer Relationship Management (eCRM) is one of the primary strategic initiatives in industry today with co-existing criticism and over-enthusiasm. There is a rapidly increasing number of reports on eCRM implementation failure and success; these reports, however, are all in piecemeal form. This research aims to systematically explore the current status of eCRM implementation status in practice and the critical success factors that affects the eCRM survivability, eg continued use of an eCRM system reaching intended profitability or growth. 180 companies in 12 industries were surveyed and 36 in-depth interviews were conducted to gain insights toward companies' eCRM implementation. Findings from this research indicate that companies implement eCRM for different reasons, and that eCRM implementation brings both tangible and intangible benefits to the companies. Six major success factors of eCRM were identified and discussed. These results shed meaningful light on how the survivability of an eCRM strategy can be assessed and then improved, if necessary. The research results are formalised in a conceptual eCRM survival model that helps guide companies' eCRM strategies.
\end{abstract}

Qimei Chen

Department of Marketing, College of Business Administration, University of Hawaii, C303, 2404 Maile Way, Honolulu, HI 96822, USA.

Tel: +1 808956 8921; e-mail: qchen@cba.hawaii.edu
'We spent $\$ 30$ million this year on ByRequest program ... This is not about earning free stuff. We want to know more about our guests so we can treat them better and offer them better choice ... We don't say, stay 10 times and you get something free. Instead, we try to meet and exceed your expectations during every stay and all the time.'

Kathy Hollenhorst, Sales and Marketing, Radisson Hotels International Inc

\section{INTRODUCTION}

Forging long-term relationships with premium customers is usually viewed as the key to profitability in an increasingly dynamic market. Electronic customer relationship management (eCRM) is one of the primary strategic initiatives in industry today. It has become the latest paradigm of relationship marketing in the e-world. Most people usually drop the ' $\mathrm{e}$ ' when speaking about eCRM, they 
generally refer to CRM (customer relationship management) that has technology-facilitated interfaces with customers in a broad e-business context which goes beyond the web. It integrates sales, marketing and service strategies that will create more value propositions for customers. It enables firms to recreate an 'old fashioned' one-to-one relationship with customers along with mass-market efficiencies from selling to millions of customers - the power of mass-customisation. It employs modern information technology - from relational databases, to data warehousing, to data mining, to computer telephony integration, to internet delivery channels - to unlock customer profitability. Sophisticated segmentation and analysis technologies, comprehensive customer interaction data, multi-channel communications and one-to-one interactions are used to market customised products and services to ever more precise segments.

Between 1996 and 2000, according to Forrester Research, ${ }^{1}$ corporate investment in eCRM technology grew at a compound annual rate of 54 per cent. However, the worldwide CRM applications market in 2002 actually shrank 25 per cent from $2001 .^{2}$ In spite of the downturns, more than half (52.6 per cent) of companies would increase their eCRM budgets through 2003 and eCRM spending is expected to increase from $\$ 2.3 \mathrm{bn}$ to $\$ 4.7 \mathrm{bn}$ by 2008 .

As reported, companies were encountering a steep learning curve when implementing eCRM systems. In the beginning, companies were enthralled by idyllic possibilities depicted by the software vendors. A knee-jerk reaction is to buy off-the-shelf applications, cobble together a database of web traffic and online purchase information and launch an eCRM initiative. Unfortunately, many such efforts have met with poor results.
Recent reports indicate that $44-60$ per cent of eCRM projects failed. ${ }^{3}$

Although it is now widely accepted that eCRM is a strategy and not just a software tool, ensuring the success of an eCRM strategy, which entails the change of organisational culture, business processes, technological infrastructure and employee behaviours to support the coordinated interaction with customers throughout all channels, still remains unclear to corporations. ${ }^{3}$ Piecemeal reports on eCRM implementation failure and success have been insufficient in their empirical, cross-industry examination of eCRM success factors. This research aims to explore the current adoption of eCRM in practice and discovering critical success factors that affect the eCRM survivability. A conceptual eCRM survival model is presented as a result of the study to guide companies in eCRM strategy implementation.

\section{RESEARCH MOTIVATION AND RESEARCH QUESTIONS}

Understanding what factors affect system success is critical to determine management actions and information technology (IT) investment, including information system (IS) design. Due to the importance, complexity, multi-dimensionality and scope of the organisational commitment of today's eCRM applications, the authors' research inquiry is to uncover what new factors and new issues face business and IT managers in achieving eCRM success, and whether the companies have realised the importance and benefits of eCRM implementation.

Although eCRM is a relatively new application, the study of system success is quite common in IS research. Many frameworks for studying IS success exist; and this study utilises the construct of 
'net benefit' in the widely applied and tested DeLone \& McLean IS Success Model. ${ }^{4}$ After examination of 150 empirical experiments that applied this model from 1992 to 2002, DeLone and McLean revised their model to group all (individual and organisational) impact measures into a single impact or benefit category called 'net benefits', which is the final success variable in their model. In this research, the authors aim to understand what net benefits companies have realised in practice and cross-industry to drive the continued investment and strategic use of eCRM systems. In addition, the strategic intent of adopting eCRM systems must be examined to understand if there is an 'adoption emulation' effect regarding eCRM application, where companies just went in a 'fad' without a strategic plan in mind with regard to their investment in eCRM. This phenomenon reportedly contributes to new technology adoption failure. To sum up, the authors aim to address the following three questions in this research:

1 What are companies' strategic intents in adopting eCRM?

2 What are the 'net benefits' realised by companies across industries?

3 What are the common eCRM critical success factors recognised by companies across industries?

\section{METHODOLOGY}

\section{Selection of the firms}

The research questions were examined through an empirical survey of 180 companies and exploratory in-depth interviews of 36 firms.

The selection of the firms followed several stages.

In the first stage, 12 industries that were most likely to employ eCRM strategies were identified by experts. These industries include retail management, photography, office supplies and equipment, hospitality, financial services, telecommunications, computer hardware/software, consumer electronics, entertainment and media, apparel, healthcare and sports. All these industries face the intensive competitive pressures of better customer relationship management and, therefore, may share similar interests in adopting eCRM systems. The authors arbitrarily decided to choose 15 companies in each industry, with an even number of small, medium and large companies; five mid-size companies (revenue $\leqslant \$ 25 \mathrm{~m}$ ), ie five small-size companies, five mid-size companies (revenue $\$ 25 m-1 b n$ ) and five large-size companies (revenue $\geqslant \$ 1 \mathrm{bn}$ ). The authors contacted companies in each industry for their cooperation in participating in the survey. They kept making contacts until 15 companies of various sizes in each industry agreed to participate. Hence, a list of 180 companies that have/intend to have an eCRM practice was finally generated. To fathom the level of companies' eCRM practice, the authors asked the companies to self-report their employment of various eCRM systems. For instance, companies reported whether they currently had a web-based eCRM practice, and what type of eCRM they were employing.

In the second stage, the eCRM project managers in each company were contacted to solicit their answers to questions such as the current number of employees involved in eCRM; how long they have been using or have been intending to use eCRM, eCRM investment, eCRM project scope, and eCRM usage rate.

In the third stage, three companies (one for each size) from each of the 12 industries were interviewed. A total of 
36 eCRM project managers were contacted for an in-depth interview about their eCRM development. These interviews helped answer why and how eCRM is adopted in the firm; what the current status of eCRM system is in the company; what benefits the eCRM system has generated for the company; what the critical success factors perceived by the company and in their eCRM implementation; what barriers have prevented more extensive use of eCRM in the company; and, finally, the companies' plans for future use or expansion of eCRM.

In the fourth stage, an eCRM strategy survival model is conceptualised based on the insights from the empirical in-depth interview. Theoretical implications as well as strategic implications of this model are then discussed.

\section{Data collection}

As mentioned earlier, both qualitative (eg open ended interviews) and quantitative (eg response forms with quantified responses) methods were used ${ }^{5}$ with multiple respondents in each firm to achieve triangulation of data and insights. $^{6}$

\section{FINDINGS}

Twenty-four-hours of interview responses were transcribed from audio tapes to text files. The files were then coded and the content analysed. Preliminary findings are summarised in Table 1. The table shows the industries surveyed, the one sample company interviewed in each industry and the eCRM source and reasons for implementing eCRM for each company.

For instance, Shop at Home Inc mentioned that its motivation for implementing eCRM is to understand what the consumers want and then deliver it, while ToysN'Joys wants to keep its consumers' informed, and the Limited Inc is aiming at leveraging the brand equity across multiple channels. A closer look at these companies shows that although each company adopted eCRM for slightly different reasons, their general goal is customer-oriented, which is in line with the basic assumption or design intention of eCRM systems. This also explained the current proliferation of eCRM systems that provide different functions.

\section{Current eCRM adoption and net benefits}

Managers regard eCRM as very important for achieving business success. On average, they gave a mean score of 9.2 on a scale from 1 to 10 (with 10 the highest). In addition, the results from the survey of 180 companies also show that eCRM is a means of taking better care of customers for large companies, an efficient communication channel for medium companies and a marketplace to meet more consumers for small companies, and that the current eCRM systems implementation varies significantly. Some of the current systems are not yet fully-fledged systems. The types of eCRM system implementation could range from purely informational, where the organisation employs web-based non-interactive customer services (listing a 1-800 number), to operational, where the consumers make product purchases and financial transactions (ie Office Depot), to analytical where the organisations have tools to help what-if analysis and personalisation (for instance, Land's End allows customised visualisation of the clothing picked), to collaborative where the organisation provides a discussion forum or human agents to communicate via various communication channels to assist with 
Table 1 eCRM industries and their representative companies

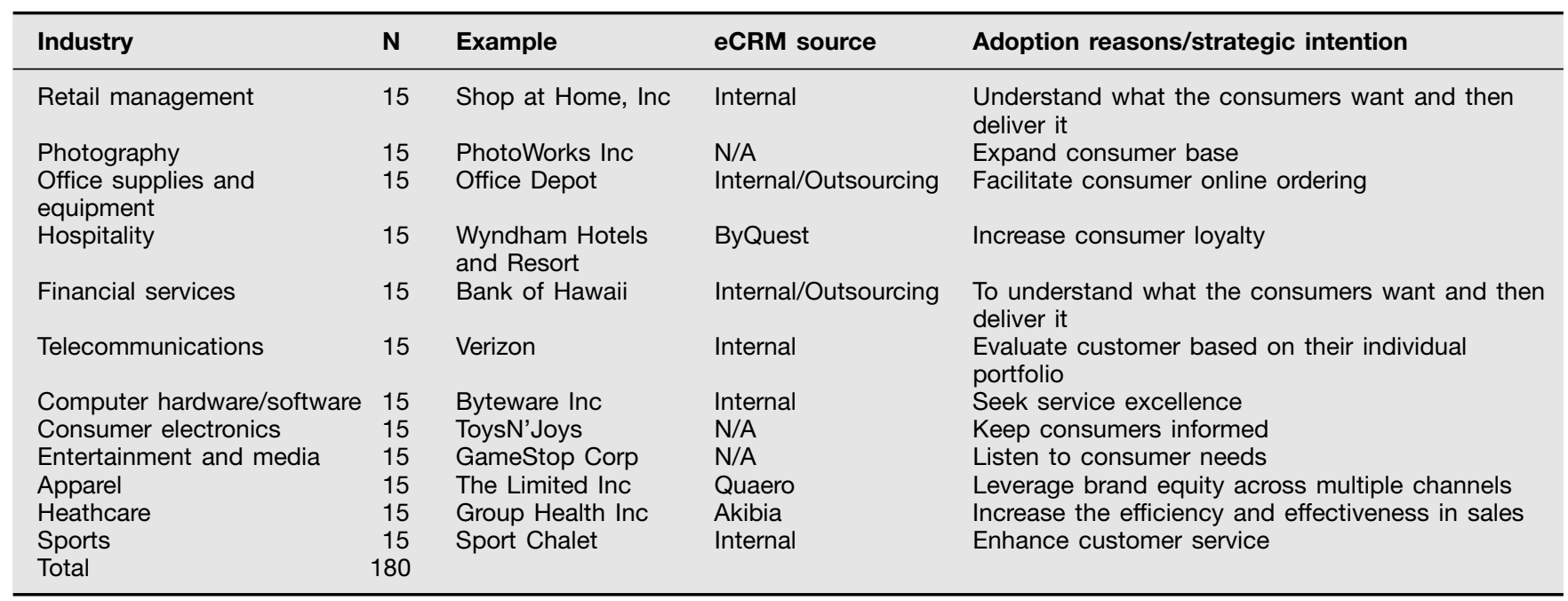

tasks with higher complexity (ie Verizon).

The companies surveyed were able to articulate their strategic intents and the authors did not find cases where the adoption of eCRM was purely to 'jump on the bandwagon'. Confirming a previous study, ${ }^{7}$ managers agree that an eCRM application brings a host of benefits to their organisations. These benefits are categorised as tangible and intangible benefits (see Table 2). The tangible benefits of eCRM mentioned by managers include increased revenues and profitability, quicker turnaround time, reduced internal costs, higher employee productivity, reduced marketing (eg direct mailing) costs, higher customer retention rates and protected marketing investment with maximised returns. The intangible benefits include increased customer satisfaction, positive word-of-mouth, improved customer service, a streamlined business process, closer contact management, increased depth and effectiveness of customer segmentation, acute targeting and profiling of customers and better understanding/addressing of customer requirements.

The following case study illustrates the tangible as well as intangible benefits eCRM could bring to a mid-size healthcare business.

Group Health Incorporated (GHI) is the largest statewide, not-for-profit health services corporation. It supplies an array of health insurance plans and third-party administrative services for group and individual subscribers. It serves 2.6 million people and managed a 97 per cent member retention rate. In 2001, it had a net income of $\$ 29.4 \mathrm{~m}$. As GHI is facing furious competition in the health insurance industry, which has high customer turnover rate, the efficiency of their sales representatives' is essential for GHI to sustain its leadership in this industry. Before eCRM, GHI's sales representatives spent too much time on paperwork (memos, faxes, requests, letters). It was also too labour intensive for GHI's sales representatives to access customer information and research information in their original multiple legacy system. Furthermore, its two sales divisions (upstate and downstate NY) 
Table 2. eCRM benefits

\begin{tabular}{ll}
\hline Tangible Benefits & Intangible Benefits \\
\hline - Increased revenues and profitability & - Increased customer satisfaction \\
- Quicker turnaround time & - Positive word-of-mouth \\
- Reduced internal costs & - Improved customer service \\
- Higher employee productivity & - Closer contact management \\
- Reduced marketing (eg direct mailing) costs & - Increased depth and effectiveness of customer \\
- Higher customer retention rates & segmentation \\
- Protected marketing investment with maximised & - Acute targeting and profiling of customers \\
returns & - Better understanding/addressing of customer \\
& requirements \\
\hline
\end{tabular}

developed separate sales processes over time and their customers started to complain that the responses to their email inquiries were too slow. The solution to the problems is the Siebel eHealthcare system, developed, deployed and supported by Akibia. This eCRM system consists of five integral parts: Enterprise Integration Manager, Siebel Literature and Correspondence, Electronic Activity Management, Siebel Remote and Siebel eMail Response. The results of this eCRM adventure are very apparent; GHI now enjoys a higher employee productivity and reduced marketing costs. Its consumers are happier because they have found that GHI's sales agents are more responsive now. GHI has ambitious plans to extend its eCRM capability to its entire sales process in the future. It is looking forward to allowing brokers and administrators to conduct all aspects of business online, eg submit group information, receive quotes, enrol members, obtain certificates and check benefits.

This case demonstrates the system quality, data quality and services quality resulting from successful system integration. Both internal customers and external customers enjoyed the benefits of eCRM which leads to the future expansion of GHI's eCRM implementation scope.

\section{Critical eCRM success factors}

The focal point of this research is to solicit the eCRM critical success factors from the managers' point of view. To achieve this purpose, critical incidence technique was employed to facilitate managers' thinking process. ${ }^{8}$ A rich set of critical success factors is yielded from the interviews. These critical success factors are then coded and grouped into meaningful dimensions. Overall, six critical success dimensions emerged from the interviews. They are: first class leadership, organisational perceived usefulness, knowledge management, business-IT alignment, system integration, and culture/structure change.

Table 3 illustrates the six major eCRM critical success factors as well as the detailed items that emerged from the interviews.

For instance, culture change dimension consists of three sub-factors: customer service consciousness, customer-centric organisation culture and consumer-focused marketing strategies. Culture change as a dimension emerged from our in-depth interviews as an important critical success factor. The importance of this factor is evidenced in the interview with the Bank of Hawaii. As mentioned previously, multiple respondents in each firm were interviewed to achieve triangulation of data and insights. ${ }^{6}$ The Vice Chairman of 
Table 3: eCRM critical success factors

\begin{tabular}{|c|c|}
\hline Major Dimensions & Items \\
\hline Champion leadership & $\begin{array}{l}\text { - Organisational commitment } \\
\text { - Management leadership } \\
\text { - Management support }\end{array}$ \\
\hline Internal marketing & $\begin{array}{l}\text { - Incentive } \\
\text { - Training and re-training }\end{array}$ \\
\hline Knowledge management & $\begin{array}{l}\text { - Knowledge about customers } \\
\text { - Knowledge about market segments } \\
\text { - Knowledge about competitors } \\
\text { - Data mining } \\
\text { - Personalisation }\end{array}$ \\
\hline Business-IT alignment & $\begin{array}{l}\text { - IT strategies supporting business strategies } \\
\text { - Customer-centric interface design } \\
\text { - Technical architecture reliability } \\
\text { - Technical architecture scalability } \\
\text { - Business processes matching IT architecture }\end{array}$ \\
\hline System integration & $\begin{array}{l}\text { - Functional integration: marketing, sales, customer service } \\
\text { - Data integration } \\
\text { - System compatibility } \\
\text { - Comparable experience to offline CRM } \\
\text { - Integration with other CRM channels }\end{array}$ \\
\hline Culture/structure change & $\begin{array}{l}\text { - Customer service consciousness } \\
\text { - Customer-centric organisation culture } \\
\text { - Consumer-focused marketing strategies } \\
\text { - Affiliation } \\
\text { - Merger and acquisition }\end{array}$ \\
\hline
\end{tabular}

Technology and Operations, Gretchen Mohen, and the Internet Channel Manager, Mike Curtis, were both interviewed for this purpose.

Bank of Hawaii started to adopt eCRM in 1995, which puts them 18-months ahead of their competitors in terms of internet banking. Bank of Hawaii directed a decent amount of corporate resources to eCRM. For instance, it has four employees working in the company's specialised call unit, 50-70 employees working in the general electronic Bank of Hawaii ('e-bankoh') unit. Bank of Hawaii currently uses an email response management system (ERMS) to guarantee e-mail turnaround in 24 hours. Its excellent eCRM commitment could be seen in the recent 'Tell Mike' campaign. Mrs Mohen and
Mr Curtis believe that one of their 'secret' success factors is to have a organisational culture that facilitates the growth of the customer service mentality. They felt that only aided by a customer-centric organisational culture, could they design consumer-focused marketing strategies that would make small and fast differences for the customers.

The system integration dimension consists of sub-factors such as functional integration, data integration, system compatibility, experience comparability to offline CRM and integration with other CRM channels.

The knowledge management dimension consists of sub-factors such as knowledge about customers, knowledge about market segments, 
knowledge about competitors, data mining and personalisation. In fact, system integration and knowledge management are the most frequently mentioned critical success factors in the study. The strategic importance of these two dimensions is evidenced in the following case study.

Land's End (a large apparel company) adopted eCRM to decouple the tight interdependence between technical architecture and business process; to leverage the abundance of data disbursed across existing multiple systems; to replace legacy infrastructure and contradictory, hard-coded business rules, and to enhance customer segmentation and targeting capabilities. Land's End has changed its old database system (a Mainframe OS390 system) to an open architecture IBM USE-EE AIX system. eCRM has empowered marketing staff to manage design, development and the execution of marketing campaigns, to leverage the abundant data from multiple locations - moved to flexible, open systems environment - and to integrate several existing systems and processes, which has lead to a boost in the depth and effectiveness of its customer segmentation. Land's End retired five old systems, which were replaced by Affinium Campaign. Affinium, and the completion of Lands' End customer datamart, enabled Land's End to gain a greater knowledge of customer buying behaviour, therefore, providing a better knowledge about market segments to the marketing staff. In the future, Land's End plans to enhance revenue through catalogue operations. It plans to have event-driven campaigns where the software detects a trigger (action or inaction) on the part of the customer and executes predefined campaigns or stream-based or longitudinal campaigns where contacts can be made over time.
Affinium Campaign can support multiple versions of mailings. Hence Land's End can execute customised, individualised mailings, which helps to reduce overall production costs.

Another business in the apparel business, Saks Incorporated, also benefits from knowledge management. Like Land's End, Saks enjoyed the benefits of personalisation for customers in the knowledge management dimension. In addition, Saks also aligned business processes to match its IT architecture (business-IT alignment dimension), which allows it to operate under various brand names with tailored personalised services to customers in different segments.

Saks incorporated operates more than 200 stores under the names of: Saks Fifth Avenue, Proffitt's, McRae's, Yonkers, Parisian, Herberger's, Carson Pirie Scott, Bergner's, Boston Store Club Libby Lu and Off 5 th. It offers a broad selection of upper-moderate to better fashion apparel, shoes, accessories, jewellery, cosmetics and decorative home furnishings. In 2001, Saks Inc collected a net income of $\$ 75,200,000$. Saks' eCRM solution is aimed at turning its three call centres in Mississippi, Illinois and Maryland into a single virtual contact centre. The skill-based routing and data-directed routing enable Saks to personalise service for its 'gold' customers; it identifies them by dialled number identification service (DNIS), puts them at the head of the call queue and routes their calls to a special group of agents. Saks employs software that links the three-mirrored sites for intelligent call routing and load balancing. Enterprise reporting makes it possible to manage the three locations as a single resource for optimum efficiency and productivity. This eCRM implementation increased the productivity by 40 per cent and the single contact centre saved $\$ 1,000,000$. 


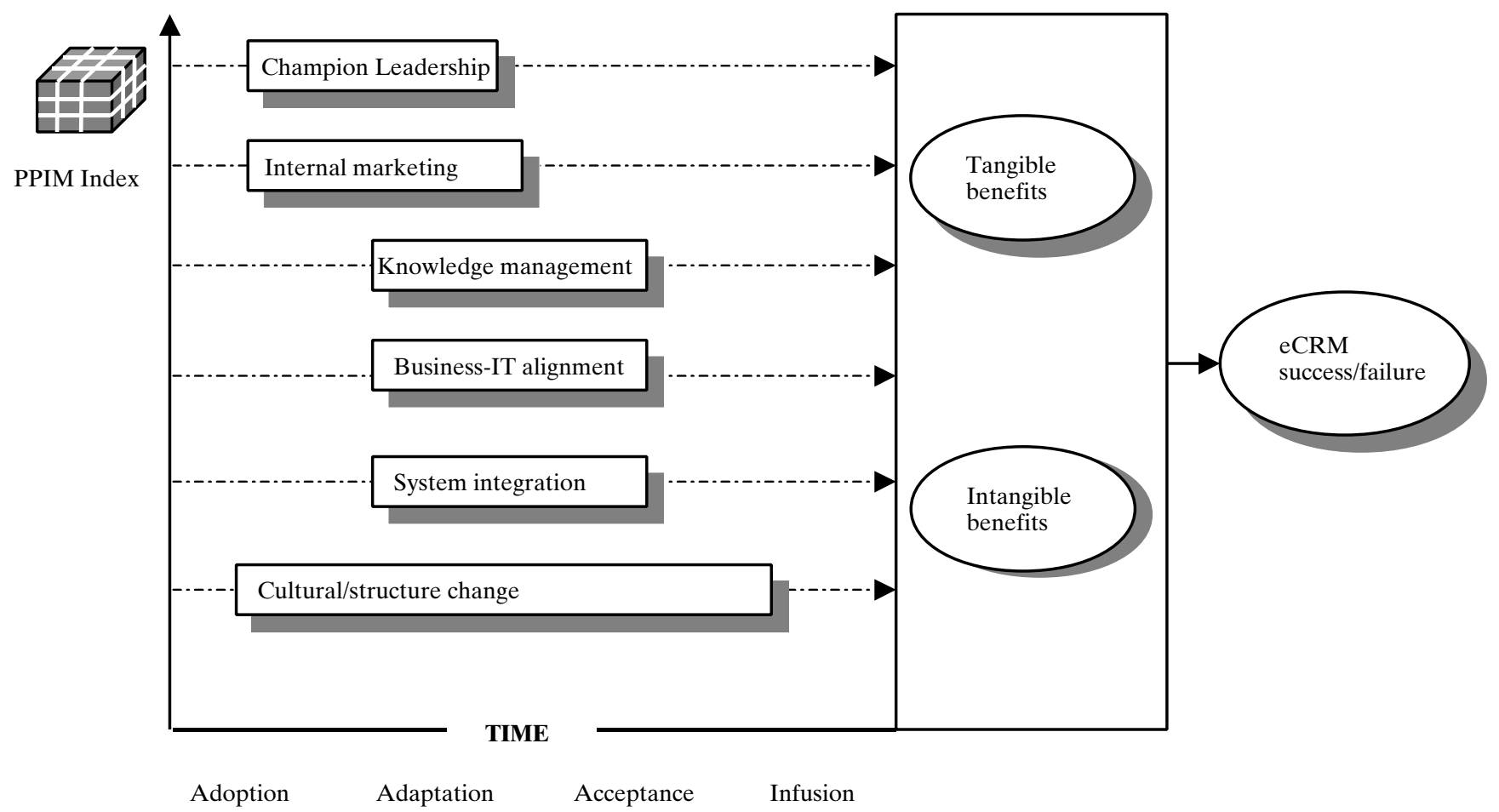

Figure 1: The conceptual eCRM survival model

\section{CONCEPTUAL ECRM SURVIVAL MODEL}

Based on the insights gathered in the 180 surveys and 36 in-depth interviews, an eCRM survival model (see Figure 1) was conceptualised on the empirical findings. This framework maintains that eCRM success is the result of the function of success factors over time, and that this function will be mediated by the tangible as well as intangible benefits of the eCRM implementation.

The six dimensions of eCRM success factors are located in a time $\mathrm{X}$-axis to illustrate the relative importance of their occurrence in the diffusion process (eg adoption, adaptation, acceptance and infusion stages). Champion leadership and internal marketing and culture/structure change factors must be attended to from the very beginning of the adoption phase while knowledge management and system integration and business-IT alignment factors are relatively more important during the adaptation phase.

In addition, the conceptual eCRM survival model considers eCRM adventure based not only on the possible sequence of their occurrence in the diffusion process but a Project Phase Identification Matrix (PPIM) score. As depicted in Figure 1, the critical success factors are distributed in a PPIM Y-axis.

The empirical findings from the present study indicate that companies' eCRM projects are different according to their industry, their size, their niches; in particular they differ from each other in terms of usage rate, investment and project scope. The authors therefore created the PPIM index in this model to indicate the interactive aspect of the critical success factors (CSFs) and PPIM. This matrix consists of three axes: eCRM 


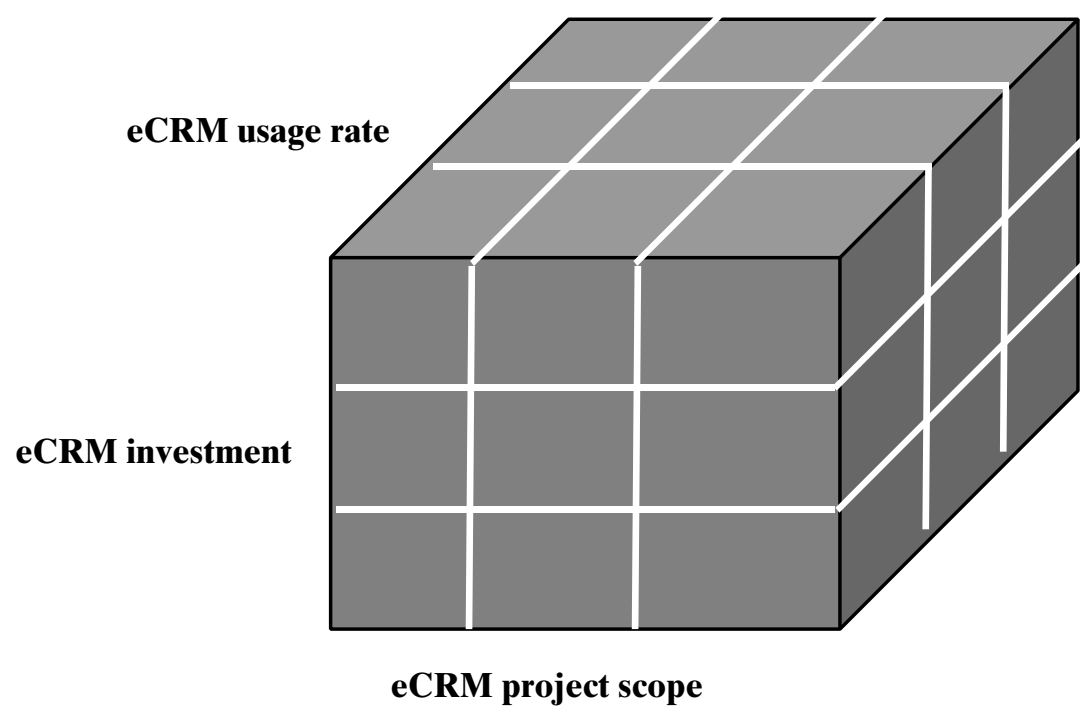

Figure 2: eCRM project phase identification matrix (PPIM)

usage rate, eCRM investment and eCRM project scope (see Figure 2). eCRM

investment is defined as the percentage of the money invested on an eCRM project in proportion to the total revenue of the firm; eCRM project scope is defined as the number of functional areas of the company currently employing eCRM; eCRM usage rate is defined as the degree of eCRM adoption in the firm (how often the system is being used in relation to other systems in place).

The proposed conceptual eCRM survival model is based on the empirical insights yielded by the survey and in-depth interviews. It could be used as a functional tool for firms implementing of intending to implement eCRM. Specifically, for firms intending to adopt an eCRM system, this model serves as a prescriptive tool, helping to outline an eCRM implementation plan to direct the future systematic implementation. For firms that have already implemented an eCRM system, this model works as a diagnostic tool to chart current eCRM progress and to guide future improvement.

\section{DISCUSSION AND CONCLUSION}

Although eCRM sometimes has been categorised as part of general $\mathrm{CRM}^{9}$ it nevertheless presents a unique challenge in terms of assessing its benefits and charting its success. This study has contributed to understanding the implementation of eCRM applications across 12 industries and providing a comprehensive summary of the net benefits of the eCRM system in practice. Furthermore, six critical success dimensions were concluded from the in-depth interviews.

Theoretically, these findings imply that companies adopt eCRM for different reasons. For instance, some adopted eCRM to increase consumer loyalty, others adopted eCRM to leverage brand equity across multiple channels. In line with the structuration theory, ${ }^{10,11,12}$ these insights reflect the importance of understanding the 'spirit' (general intent) of the technology. This understanding will further assist the future design of eCRM systems to accommodate the intended 'spirit' of eCRM of different companies. 
Strategically, the current findings indicate that system integration and knowledge management are the most frequently mentioned CSFs among companies interviewed. The emphasis of the importance of these two factors helps to forecast the future trend of eCRM implementation. Further, the authors' model validated many CSFs in IS adoption and implementation, and found several dimensions that must be emphasised for eCRM applications. In particular, internal marketing is a critical aspect which had not been emphasised in previous IS implementation. The business-IT alignment dimension highlights the need for a holistic view of business models, system architecture and integration of business and IT strategies.

Finally, the eCRM critical success factors and eCRM benefits identified in the empirical investigation serve as fundamental building blocks in formulating the conceptual eCRM survival model. This model has theoretical and strategic implications for practitioners as well as IS researchers. This model provides understanding of CSFs for eCRM applications and the factors' association with different stages of the technology diffusion process and project phase. This association of CSFs with technology infusion and PPIM serves as a timely intervention to help the survival of eCRM strategies. This study, therefore, helps organisations to gain control over the course of eCRM deployment and thus decreases the alarming rate at which eCRM projects fail.

\section{References}

1 Chatham, R., Weisman, R. D. E., Orlov, L. M., Nakashima, T. and Howard, E. L. (2001) 'CRM: At What Cost?', Forrester TechStrategy Report, March 2001, www. forrester.com.

2 Cosgrove Ware, L. (2003) 'CRM: Desperately seeking success', CIO Magazine. August 1, 2003, www.cio.com/archive/080103/tl-numbers.html

3 Gartner Group (2001) 'Customer Relationship Management: Building Stronger, More Profitable Customer Relationships', available at www.gartner.com.

4 DeLone, W. H. and McLean E. R. (2002) 'Information Systems Success Revisited', Proceedings of the Thirty-Five Annual Hawaii International Conference on System Sciences, Vol. 8, pp. 238.

5 Kaplan, B. and Duchon, D. (1988) 'Combining Qualitative and Quantitative Methods in Information Systems Research: A Case Study', MIS Quarterly, Vol. 12, No. 4, pp. 571-586.

6 Benbasat, I., Goldstein, D. K. and Mead, M. (1987) 'The Case Research Strategy in Studies of Information Systems', MIS Quarterly, Vol. 11, No. 3, pp. 369-386.

7 Conlon, G., Myron, D., Picarille, L. and Rasmusson, E. (2003) 'Preview 2003 - What's in Store for CRM?', CRM Magazine, January, http://www.destinationcrm.com/articles/ default.asp? Article ID $=2770$.

8 Herzberg, F. (1968) 'One More Time: How Do You Motivate Employees?' Harvard Business Review, Vol. 46, January-February, pp. 53-62.

9 Pass, L. and Kuijlen, T. (2001) 'Towards a General Definition of Customer Relationship Management', Journal of Database Marketing, Vol. 9, No. 1, pp. 51-60.

10 Barley, S. (1986) 'Technology as an Occasion for Structuring: Evidence from Observations of CT Scanners and the Social Order of Radiology Departments', Organization Science, Vol. 1, No. 3, pp. 220-247.

11 Orlikowski, W. J. (1992) 'The Duality of Technology: Rethinking the concept of Technology in Organizations', Organization Science, Vol. 3, No. 3, pp. 398-427.

12 Orlikowski, W. J. and Robey, D. (1991) 'Information Technology and the Structuring of Organizations', Information Systems Research, Vol. 2, No. 2, pp. 143-169. 